\title{
ANALISIS KUALITAS PERBAIKAN CITRA MENGGUNAKAN METODE MEDIAN FILTER DENGAN PENYELEKSIAN NILAI PIXEL
}

\author{
Haruno Sajati \\ Program Studi Teknik Informatika \\ Sekolah Tinggi Teknologi Adisutjipto Yogyakarta \\ harunosajati@stta.ac.id
}

Abstract

Median Filter method is one method of image quality enhancement in spatial domain. Spatial domains have advantages on image result quality because the image fixedpixel by pixel. Because image enhancementprocess to pixels, Median Filter methods have high computation and long execution time.By selecting the pixels of images that need to be repaired can reduce the processing time and improve the image quality because the correctpixels does not need to be repaired. Image quality measurement is calculated using Peak Signal to Noise Ratio (PSNR) by comparing the original image value with image of improvement. Image enhancement using median filter for all pixel has PSNR value $28.5 \mathrm{~dB}$ meanwhile with pixel filtering has PSNR value $30.1 \mathrm{~dB}$ or increase by $5.61 \%$. Time process for image enhancement for all pixel are 2.12 second meanwhile with pixel filtering are 1.94 second or reduces $8.5 \%$. Because PSNR value of image enhancement are above $30 \mathrm{~dB}$ then this image result feasible for next process.

Keyword: Median Filter, pixel, PSNR.

Abstrak

Metode Median Filter adalah salah satu metode perbaikan kualitas citra pada domain spatial. Domain spatial memiliki kelebihan pada hasil perbaikan karena perbaikan citra dilakukan per-pixel.Karena perbaikan citra dilakukan terhadap pixel, metode Median Filter memiliki komputasi yang tinggi dan waktu eksekusi yang lama. Dengan melakukan penyeleksian terhadap pixel yang perlu diperbaiki dapat mengurangi waktu proses perbaikan dan meningkatkan kualitas citra karena pixel yang sudah benar, tidak perlu diperbaiki. Pengukuran kualitas citra dilakukan menggunakan Peak Signal to Noise Ratio (PSNR) dengan membandingkan nilai citra asli dengan citra hasil perbaikan. Perbaikan citra menggunakan median filter pada semua pixel memiliki nilai PSNR 28.5 dB sedangkan dengan penyeleksian nilai pixel memiliki nilai PSNR $30.1 \mathrm{~dB}$ atau meningkat 5.61\%. Untuk waktu perbaikan citra pada semua pixel membutuhkan 2.12 detik sedangkan dengan penyeleksian nilai pixel membutuhkan 1.94 detik atau turun $8.5 \%$. Kualitas hasil perbaikan citra dengan menyeleksi nilai pixel dianggap layak untuk proses berikutnya karena sudah di atas $30 \mathrm{~dB}$.

Kata Kunci : Median Filter, pixel, PSNR.

\section{Latar Belakang Masalah}

Salah satu tahap dalam image preprocessingadalah menghilangkan informasi yang tidak diperlukan seperti gangguan (noise) (Abdullah dkk, 2016). Tujuannya adalah agar citra siap untuk diolah pada tahap berikutnya seperti computer visionatau pengenalan pola informasi dalam citra tersebut. Tahap image preprocessing ini memerlukan beban dan waktu komputasi yang cukup tinggi sehingga menghambat proses berikutnya. 
Sebuah citra harus memiliki kualitas yang cukup baik untuk pemrosesan lebih lanjut. Apabila kualitas citra yang akan diproses tidak baik, maka akan berakibat pada kesalahan pemrosesan citra tersebut. Kualitas citra ditentukan dari berapa nilai rasio gangguan terhadap citra aslinya. Oleh sebab itu citra harus ditingkatkan kualitasnya terlebih dahulu sebelum citra akan diolah.

Metode Median Filter adalah salah satu teknik dalam pengolahan citra pada domain spasial yang dapat digunakan untuk peningkatan kualitas citra (image enhancement) terutama mengurangi noise (distorsi) pada sebuah citra (Jeon dkk, 2015). Nilai median dari sebuah picture element (pixel) dihitung dengan menyortir nilai pixel yang berada di sekitar nilai yang akan difilter (Sharma, Pritamdas, 2016). Metode Median Filter akan melakukan perubahan terhadap semua pixelpada sebuah citra. Hal ini menyebabkan proses perbaikan citra yang semakin lama, komputasi yang semakin berat (Wang dkk, 2003) dan hasil yang sia-sia. Proses Median Filter terhadap semua pixel justru menyamarkan citra asli yang sebenarnya sudah benar dan tidak perlu diperbaiki dan justru menyebabkan turunnya kualitas citra hasil perbaikan.

\section{Metodologi Penelitian}

Pada makalah ini, Median Filter hanya dilakukan jika nilai perhitungan hasil filter memiliki nilai lebih besar dari toleransi yang diberikan. Dengan kata lain, penyeleksian pixel yang diperbaiki akan mempercepat proses perbaikan citra, mengurangi beban komputasi dan kualitas hasil yang lebih baik. Langkah percobaan yang dilakukan adalah:

a. Memberikan noisedengan tipe salt and pepper pada citra asli;

b. Memperbaiki citra noise menggunakan metode median filter dengan membandingkan pixel asli dengan pixel hasil perhitungan Median Filter;

c. Mengukur kualitas citra dilakukan dengan menghitung nilai Mean Square Error (MSE) dan Peak Signal NoiseRatio (PSNR) dengan membandingkan antara citra hasil perbaikan dengan citra asli.

\subsection{Prinsip Kerja Perbaikan Kualitas Citra}

Perbaikan citra menggunakan metode Median Filter ditunjukkan pada diagram alir di Gambar 1 sebagai berikut.

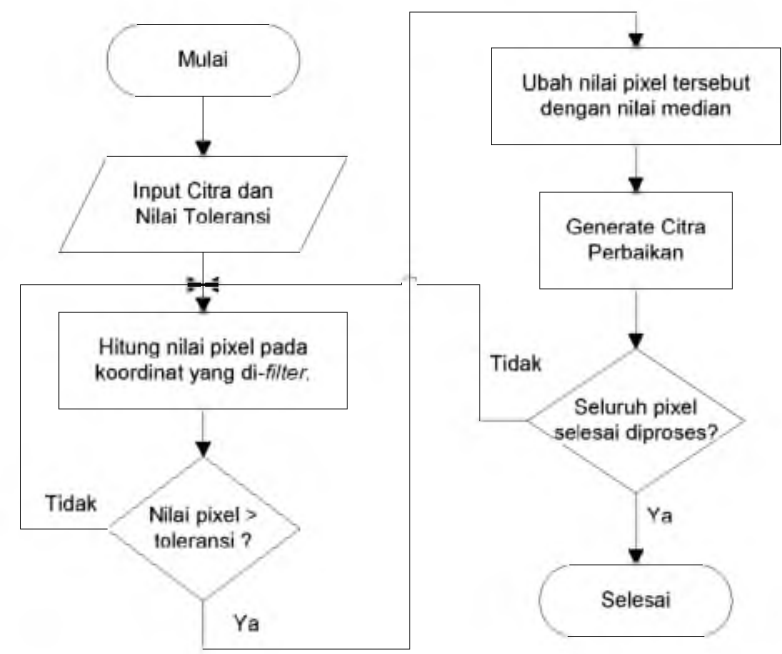

Gambar 1. Diagram Alir Perbaikan Kualitas Citra Dengan Median Filter

Nilai tetangga adalah nilai pixel di sekitar pixel yang sedang diproses. Kedelapan nilai tetangga ditunjukkan pada Gambar 2 sebagai berikut. 


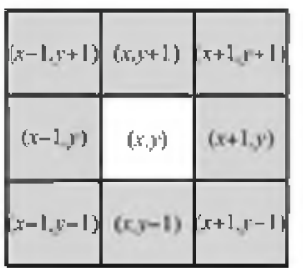

Gambar 2. Nilai Pixel Tetangga.

Median Filter diformulakan pada formula 1 sebagai berikut :

$$
y[m, n]-\operatorname{median}\left\{x[i, j],(i, j) \in u^{\prime}\right\}
$$

Pada penelitian ini digunakan delapan nilai tetangga tanpa mengkalkulasi nilai tengah $(\mathrm{x}, \mathrm{y})$ dengan asumsi sel tengah $(\mathrm{x}, \mathrm{y})$ adalah noise. Perbandingan perbaikan citra menggunakan metode Median Filter dengan melibatkan pixel tengah dengan tanpa melibatkan nilai tengah ditunjukkan pada Gambar 3 sebagai berikut:

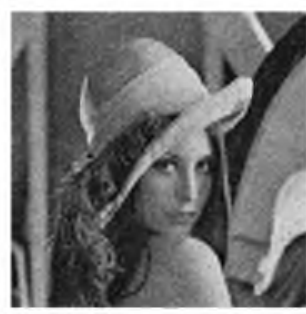

Citra Noise Salt and Pepper

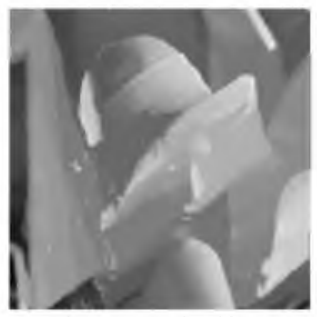

Citra Perbaikan Dengan 9 Pixel

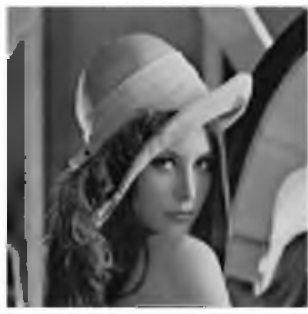

Citra Perbaikan Dengan 8 Pixel

Gambar 3. Perbandingan Kualitas Perbaikan Citra dengan Perbedaan Jumlah Tetangga

Pada formula (1) ditunjukkan bahwa nilai pixel $(m, n)$ akan dirubah dengan nilai median dari Region of Interest (ROI). Sebagai contoh pencarian nilai median dari ROI 3x3 pada Gambar 4 adalah sebagai berikut:

\begin{tabular}{|l|l|l|}
\hline 100 & 120 & 35 \\
\hline 200 & 150 & 75 \\
\hline 170 & 40 & 85 \\
\hline
\end{tabular}

Gambar 4. ROI Pencarian Median Filter

Dengan menggunakan formula (1), diperoleh nilai median dari ROI adalah :

$y(m, n)=$ ruedicu $($ sor $L(100,120,35,200,75,170,40,85))$

$y(m, n)=$ median $(35,40,75,85,100,120,170,200)$

$y(m, n)=f \operatorname{toor}\left(\frac{85+100}{2}\right)$

$y(m, n)=92$

Proses penyeleksian dilakukan dengan membandingkan antara hasil median dengan nilai pixel asli $(\mathrm{x}, \mathrm{y})$ yaitu 150 . Jika nilai selisihnya lebih besar dengan toleransi yang diberikan, maka ganti nilai asli pixel tersebut dengan nilai median filter. 


\subsection{Pengukuran kualitas Citra}

Mengukur kualitas citra digital pada prinsipnya adalah membandingkan citra yang diukur dengan citra aslinya. Kualitas citra dapat diukur dengan parameter-parameter sebagai berikut (Roopaei dkk, 2016):

a. Mean Square Error (MSE).

MSE memiliki formula yang ditunjukkan pada persamaan (2) sebagai berikut :

$$
M S E=\frac{1}{m n} \sum_{i=[!}^{J j} \sum_{j=0 !}^{J_{i}-1}[I(i, j)-K(i, j)]^{2}
$$

Dimana :

$\mathrm{m}$ dan $\mathrm{n}$ adalah dimensi citra yang akan diproses

$\mathrm{I}(\mathrm{i}, \mathrm{j})$ : Nilai pixelcitra asli pada koordinat $(\mathrm{i}, \mathrm{j})$

$\mathrm{K}(\mathrm{i}, \mathrm{j})$ : Nilai pixelcitra hasil perbaikan pada koordinat $(\mathrm{i}, \mathrm{j})$.

b. Peak Signal to Noise Ratio (PNSR)

PSNR memiliki persamaan yang ditunjukkan pada formula (3) sebagai berikut :

$$
P S N R=10 \cdot \log _{10}\left(\frac{M A X_{I}^{2}}{M S E}\right)
$$

Dimana :

MAX : Nilai pixelmaksimum pada citra asli

Nilai MSE yang diperoleh pada persamaan (2) disubstitusikan pada persamaan (3) sebagai pembagi nilai pixel maksimum pada citra asli. Nilai PSNR inilah yang menjadi pedoman apakah sebuah citra memiliki kualitas yang baik atau tidak.

Sebagai contoh sebuah citra asli dan citra asli dengan gangguan $2 \times 2$ memiliki nilai pixelgrayscale pada Gambar 5 sebagai berikut :

\begin{tabular}{|c|c|}
\hline 100 & 120 \\
\hline 173 & 40 \\
\hline
\end{tabular}

Matriks Gray Citra Asli

\begin{tabular}{|c|c|}
\hline 100 & 110 \\
\hline 150 & 40 \\
\hline
\end{tabular}

Matriks Gray Citra Noise

Gambar 5. Matriks Grey Citra

Nilai MSE diperoleh dengan menggunakan formula (2) sebagai berikut :

$$
M S E=\frac{(100-100)^{2}+(120-110)^{2}+(173-150)^{2}+(40-40)^{2}}{2 * 2}
$$

$M S E=157.25$

Nilai PSNR diperoleh dengan mensubstitusikan nilai MSE pada formula (5) dengan persamaan (3) sehingga diperoleh :

$$
\begin{aligned}
& P S M R=10 \log _{10}\left(\frac{173^{2}}{157.25}\right) \\
& P S M R=22.795 \ldots \ldots \ldots \ldots \ldots \ldots \ldots \ldots \ldots
\end{aligned}
$$


Berdasarkan nilai yang diperoleh pada persamaan (7) diperoleh kesimpulan bahwa citra noise $2 \times 2$ tersebut memiliki kualitas tidak layak untuk proses analisis berikutnya.

\section{Hasil dan Pembahasan}

Tabel 1 menunjukkan perbandingan perubahan jumlah pixel yang diperbaiki (diubah), lama proses perbaikan kualitas citra, nilai MSE dan nilai PNSR.

Tabel 1 Tabel Pengujian Perbaikan Kualitas Citra

\begin{tabular}{|c|c|c|c|c|}
\hline Toleransi & $\begin{array}{c}\text { Jumlah Pixel } \\
\text { Diubah }\end{array}$ & $\begin{array}{c}\text { Waktu Perbaikan } \\
\text { Citra(s) }\end{array}$ & $\begin{array}{c}\text { MSE } \\
\text { (dB) }\end{array}$ & $\begin{array}{c}\text { PSNR } \\
\text { (dB) }\end{array}$ \\
\hline 0 & 260100 & 2.116197801 & 90.4112587 & 28.50018527 \\
\hline 10 & 80307 & 1.971781421 & 80.11495972 & 29.02527424 \\
\hline 27 & 46665 & 1.969877533 & 62.58895874 & 30.09743316 \\
\hline 28 & 45912 & 1.967510691 & 62.60947418 & 30.09600986 \\
\hline $\mathbf{2 9}$ & $\mathbf{4 5 1 9 8}$ & $\mathbf{1 . 9 4 0 9 8 3 3 3 6}$ & $\mathbf{6 2 . 4 9 8 7 9 4 5 6}$ & $\mathbf{3 0 . 1 0 3 6 9 4 0 1}$ \\
\hline 30 & 44511 & 1.935942292 & 62.66378403 & 30.09224426 \\
\hline 31 & 43886 & 1.931244743 & 62.67712784 & 30.09131956 \\
\hline 32 & 43321 & 1.930292824 & 63.14937592 & 30.05871979 \\
\hline 50 & 35539 & 1.929081607 & 91.09004593 & 28.46770121 \\
\hline 100 & 18210 & 1.919766861 & 449.657135 & 21.53359553 \\
\hline 150 & 5611 & 1.916191745 & 1176.09206 & 17.35799724 \\
\hline 220 & 27 & 1.915464807 & 1807.664402 & 15.49123237 \\
\hline 250 & 0 & 1.897739291 & 1812.006279 & 15.48081344 \\
\hline
\end{tabular}

Pada nilai toleransi 29 merupakan hasil kualitas citra terbaik dari rangkaian percobaan. Pada nilai ini diperoleh jumlah pixel yang diubah sejumlah 45.198 buah, waktu perbaikan 1.94 detik dan nilai PSNR $30.1 \mathrm{~dB}$.

Grafik perbandingan jumlah perubahan pixel terhadap nilai toleransi ditunjukkan pada Gambar 6. Pada grafik tersebut dapat diketahui bahwa semakin tinggi nilai toleransi, jumlah pixel yang diubah semakin sedikit. Hal ini berimbas pada beban komputasi dan waktu perbaikan citra juga akan semakin cepat yang ditunjukkan pada Gambar 7.

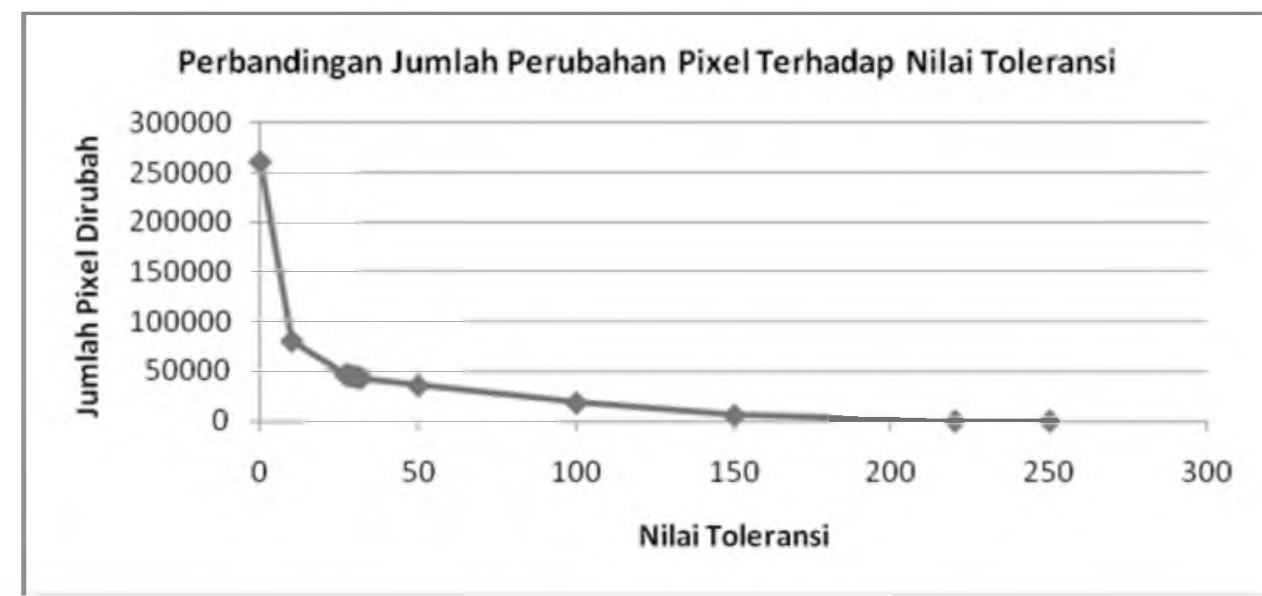

Gambar 6. Perbandingan Jumlah Perubahan Pixel Terhadap Nilai Toleransi 


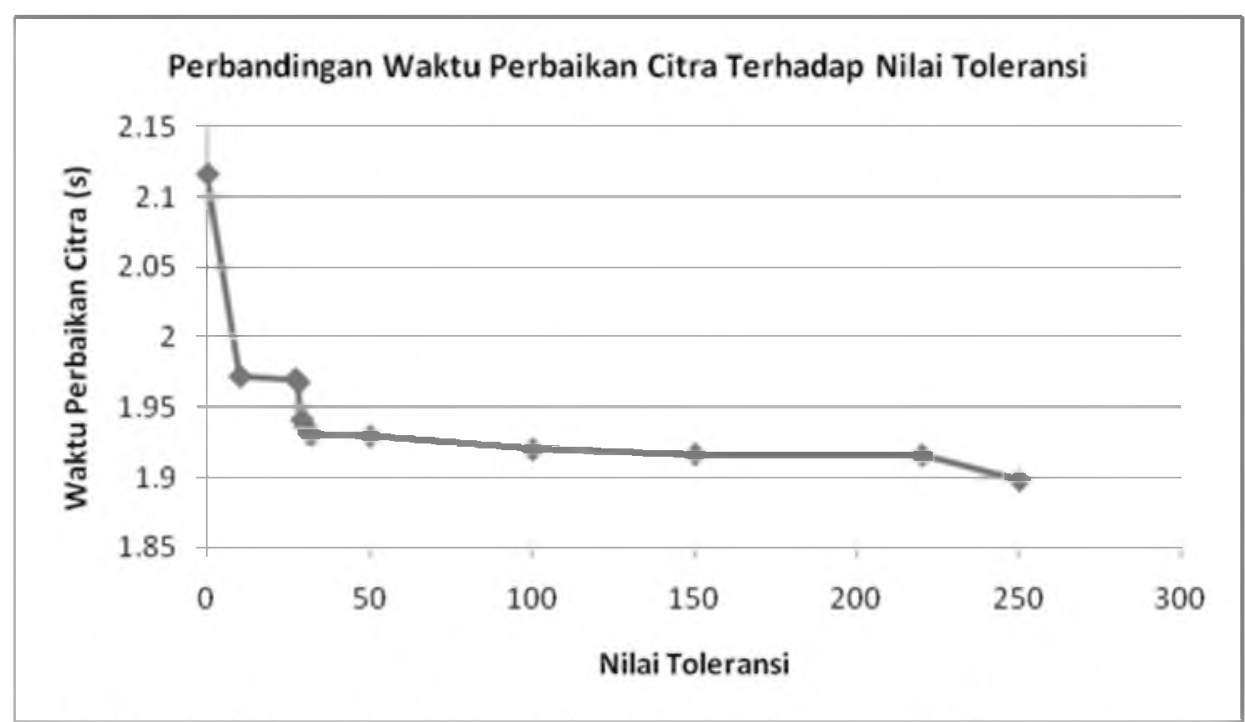

Gambar 7. Perbandingan Waktu Perbaikan Citra Terhadap Nilai Toleransi

Perubahan nilai pixel yang sedikit berakibat pada sedikitnya pixel yang diperbaiki dari citra rusak. Hal ini berakibat pada kecilnya nilai perbaikan kualitas citra (MSE dan PNSR). Citra yang baik adalah citra yang memiliki nilai MSE kecil. Semakin kecil nilai MSE, semakin mirip sebuah citra dengan citra aslinya dimana nilai tiap lokasi pixel adalah sama.

Dengan semakin kecilnya nilai MSE, maka nilai PSNR akan semakin besar. Dengan kata lain, citra dikatakan baik jika nilai PSNR di atas $30 \mathrm{~dB}$. Citra yang memiliki nilai PSNR di bawah $30 \mathrm{~dB}$ dikatakan citra tersebut mengalami degradasi dan tidak dapat dipertimbangkan untuk analisis lebih lanjut (Badshah dkk, 2016).

Dari tabel 1 dapat dilihat bahwa perubahan di setiap pixel (nilai toleransi sama dengan 0) justru memiliki nilai PSNR sama dengan $28.5 \mathrm{~dB}$ yang berarti citra tersebut tidak layak diproses lebih lanjut. berikut :

Grafik perbandingan nilai MSE dan PSNR ditunjukkan pada Gambar 8 dan 9 sebagai

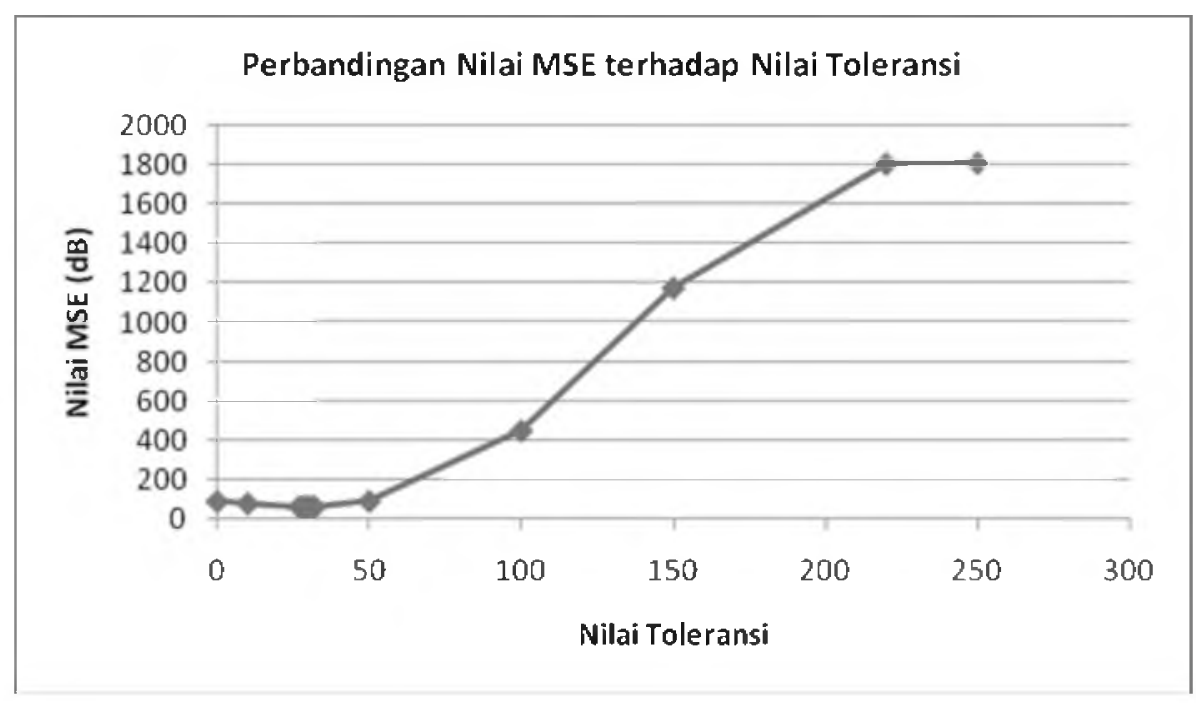

Gambar 8. Grafik Perbandingan Nilai MSE dengan Nilai Toleransi 


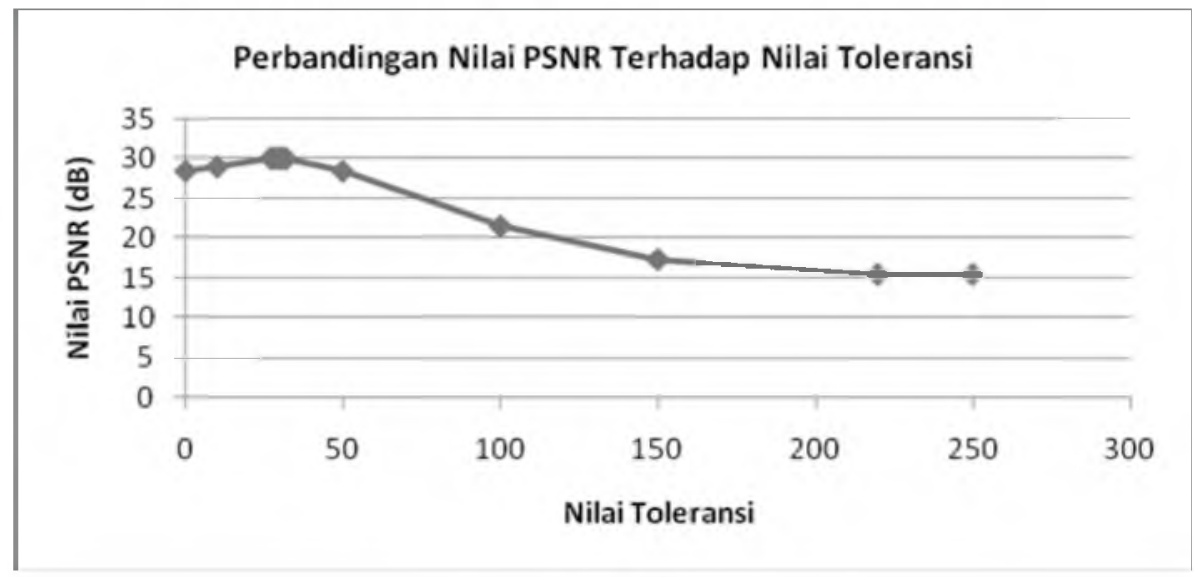

Gambar 9. Grafik Perbandingan Nilai PSNR dengan Nilai Toleransi

Perubahan nilai PSNR dirumuskan dalam formula matematis :

$y^{\prime}=-4.10^{-8} x^{4}+2.10^{-5} x^{3}-0.003 x^{2}+0.146 x+28.37$

Dari persamaan (4) diperoleh nilai puncak saat nilai toleransi adalah 29pixel dengan nilai MSE terkecil yaitu 62.49879456 dan nilai PSNR $=30.10369401$ (dB). Karena nilai PSNR sudah di atas $30 \mathrm{~dB}$ maka citra ini dapat dilakukan proses analisis berikutnya.

Perbandingan citra asli dengan citra perbaikan dengan nilai PSNR 30.1 dB ditunjukkan pada Gambar 10 sebagai berikut :

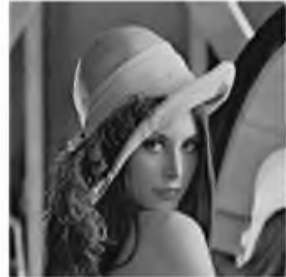

Gambar Asli

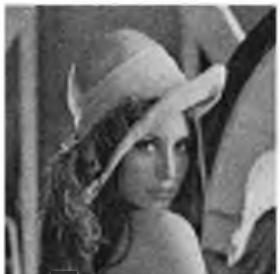

Citra Noise

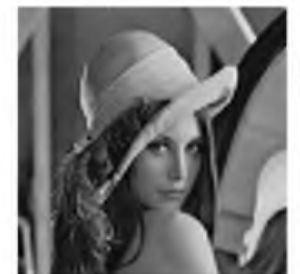

Citra PSNR 30.1dB

Gambar 10. Perbandingan Kualitas Citra Antara Citra Asli, Citra Ber-noise dan Citra Perbaikan dengan Nilai PSNR 30.1 dB

Keuntungan lain menggunakan penyeleksian pixel pada metode Median Filter adalah citra tidak mengalami pengaburan (blur) saat citra di-filter berkali-kali. Pada metode Median Filter tanpa penyeleksian, citra mengalami pengaburan setelah citra di-filter 15 kali seperti ditunjukkan pada Gambar 11.

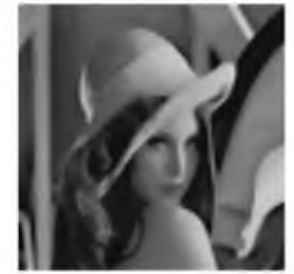

Citra Mengalami Pengaburan

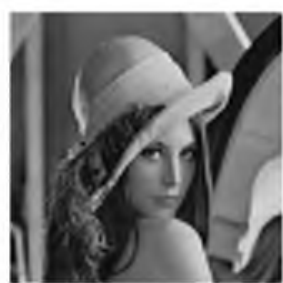

Citra Tidak Mengalami Pengaburan

Gambar 11. Perbandingan Citra Setelah Di-filter 15 Kali 


\section{Kesimpulan}

a. Perubahan seluruh nilai pixelpada citra tidak memberikan hasil terbaik. Hal ini justru menyebabkan komputasi yang cukup tinggi karena semakin banyak pixel yang harus diubah, waktu pemrosesan yang lebih lama dan kualitas hasil yang tidak baik.

b. Perbaikan kualitas citra menggunakan metode Median Filter dengan penyeleksian tidak menyebabkan citra menjadi kabur saat dilakukan 15 kali pemrosesan.

c. Perbaikan kualitas citra menggunakan metode Median Filter dengan penyeleksian memiliki kenaikan nilai PSNR sebesar 5.6\% dan memiliki kenaikan kecepatan proses perbaikankualitas citra sebesar $8.3 \%$ dibanding merubah semua nilai pixelcitra.

\section{Daftar Pustaka}

Gran Badshah, Siau-ChuinLiew, JasniMohd Zain, Mushtaq Ali, 2016, Watermark Compression in Medical Image Watermarking Using Lempel-Ziv-Welch (LZW) Lossless Compression Technique, Journal of Digital Imaging, ISSN: 0897-1889 (Print) 1618-727X (Online), Springer

Hae-GonJeon, Jaesik Park, GyeongminChoe, Jinsun Park, Yunsu Bok, Yu-Wing Tai, In So Kweon, 2015, Accurate Depth Map Estimation From A Lenslet Light Field Camera, Computer Vision and Pattern Recognition (CVPR), 2015 IEEE Conference on DOI: 10.1109/CVPR.2015.7298762

Mehdi Roopaei, MoradKhosraviEghbal, Mehdi Shadaram, SosAgaian, 2016, Noise-Free Rule-Based Fuzzy Image Enhancement, Society for Imaging Science and TechnologyIS\&T International Symposium on Electronic Imaging 2016 Image Quality and System Performance XIII IQSP-225.1 DOI: 10.2352/ISSN.24701173.2016.13.IQSP-225

S.F. Abdullah, A.F.N.A Rahman, Z.A. Abas, W.H.M. Saad, 2016, Multilayer Perceptron Neural Network in Classifying Gender using Fingerprint Global Level Features, Indian Journal of Science and Technology Vol 9(9), DOI: 10.17485/ijst/2016/v9i9/84889 ISSN (Print): 0974-6846 ISSN (Online): 0974-5645

Siddarth Sharma, K. Pritamdas, 2016, FPGA Based Efficient Median Filter Implementation Using Xilinx System Generator, International Journal of Innovative Research in Science, Engineering and Technology, ISSN(Online):2319-8753 ISSN (Print):2347$6710 \mathrm{Vol} .5$, Issue 5

Zhou Wang, Ligang Lu, Alan C. Bovik, 2003, Foveation Scalable Video Coding with Automatic Fixation Selection, IEEE Transactions On Image Processing, Vol.12, No.2, Feb. 2003 